\title{
Survey and Research on Physical Health Condition of Senior Citizens in Qingdao under the Social Background of Aging
}

\author{
Xuan Chu \\ Physical Education Department, Qingdao University of Science and Technology \\ Qingdao 266042, China \\ E-mail: paperqust@163.com
}

Received: May 23, 2011

Accepted: June 16, $2011 \quad$ Published: October 1, 2011

doi:10.5539/ass.v7n10p161

URL: http://dx.doi.org/10.5539/ass.v7n10p161

\begin{abstract}
It is discovered through a test of almost ten indexes in the four aspects of body patterning, physiological function, physical quality and health condition of senior citizens in Qingdao and a comparison between this test and previous survey results, that physical condition of female is superior to that of male. However, with growth of age, physical condition of both female and male declines, and especially overweight and decline of cardio-pulmonary function account for a great proportion, which will necessarily exert influences upon the overall health condition. With regard to the problems existing in physical health condition of senior citizens, we have to take feasible and effective measures to promote physical health of the group of senior citizens. Study of this article will provide significant guidance in carrying out fitness program and developing mass sports activities in Qingdao, and, meanwhile, will offer scientific evidence for developmental program of senior citizens sports work in Qingdao.
\end{abstract}

Keywords: Qingdao, Senior citizens, Physical health

\section{Introduction}

According to statistics by the United Nations, from 1950s in the Twentieth Century to the end of 90s in the Twentieth Century, the number of senior citizens in the world had grown by $176 \%$, whereas the number of senior citizens in China had grown by $217 \%$. However, in the coming 25 years in the Twenty-first Century, the number of senior citizens in the world will have grown by $90 \%$, whereas the number of senior citizens in China will have grown by $111 \%$. According to statistics by some population research institutions, the time required for growth of the number of senior citizens above the age of 65 from $7 \%$ to $14 \%$ is 115 years in France, 85 years in Sweden, 66 years in US, 45 years in Britain, and only 25 years in China. Development of population aging in China is fast. The phenomenon of aging is not only concerned by senior citizens, but more a reality to be faced up by young people today in the future. Thus, it is an important social problem which is concerned with the overall situation. With changes in the concept of health, people's pursuit of health is no longer confined to disappearance of disease and extension of life span, and they concentrate more on improvement of living quality and pursue perfect condition of body, spirit and social adaptation. Therefore, survey and research on physical health condition of senior citizens becomes especially important. This article makes a test on almost ten physical indexes of some citizens in Qingdao and makes a statistical analysis of the data, which offers evidence for enhancing health condition of senior citizens, constructing a scientific living means and better guiding the extensive public.

\section{Summary of population aging in China}

\subsection{Population aging}

According to stipulations of World Health Organization (WHO), those above the age of 60 are classified as senior citizens, regardless of gender, occupation, religion and so on. As for a country, there is a basic theoretical framework for classification of the types of population. An important index and demarcation line is whether population of senior citizens above the age of 65 accounts for a ratio of larger than $7 \%$ of the total population. Aging of population means that the proportion of middle-aged and senior citizens to the total population increases. Longevity and low fertility rate are the direct cause for the trend of aging of the world population. At 
the beginning of the Twentieth Century, the average life expectancy in a lot of countries was merely 40 years or so and reached 60 to 70 years by the end of this century, but the average life expectancy in some countries had surpassed 80 years by the end of this century. Extension of life span makes the number of senior citizens persistently expand and decline of fertility rate makes the total population, namely the denominator of the index of aging begin to decrease or increase with a decelerated speed. Thus, the phenomenon of aging arouses more attention. Especially, the large number of babies who were born at the initial period of transforming from a high fertility era to a low fertility era will necessarily cause the peak of aging ten years later.

\subsection{Influences of population aging}

\subsubsection{Influences of population aging on the society}

Ages of labor force population are on a continuous increase. On one hand, production experience of laborers is abundant and their technical level is also improved. On the other hand, as a result of an old age, labor forces above the age of 50 are inferior to young labor forces in terms of physical strength, energy and strength. Especially under the market economy background and in an era of knowledge-based economy, the labor forces above the age of 50 are inferior to young labor force in accepting new knowledge and new technology.

2.2.2 Population aging adding weight to the economic burden of the country, enterprises and families

With continuous increasing dependency coefficient of senior citizens, expenses of the following old-age care are on a continuous increase: retirement pension, old-age pension, hospitalization costs, nursing costs, social welfare and social relief, etc., which may bring about certain economic burden on the country, enterprises and families.

\subsubsection{Influences of population aging on family structure}

Anyway, two young only children may bite off more than they can chew to shoulder daily care and nursing of four senior citizens, so they are unlikely to satisfy improvement of life quality of senior citizens and demands of their daily care and nursing.

\subsubsection{Population aging also exerting influences upon socialization of service among senior citizens}

In the current situation when China is still at an initial stage of socialist, the productivity is underdeveloped, the social security system is not perfect, the traditional method of family caring for the aged is challenged, and once the traditional ethic morality gets attacked, senior citizens may get trapped in a helpless situation and their most basic subsistence right and health right may get seriously affected.

Nevertheless, we should also notice that although a large number of senior citizens are old, their will never declines and they are still continuing to make contributions in all walks of life. Knowledge, experience, prestige, morality and capacity of senior citizens are all precious wealth of the society. To advocate worthiness at an old age is one of the particular working strategies for aged people, which fully embodies emphasis and respect on senior citizens, and thus, should continue to be deemed as an important strategy for work of aged people. Hence, it seems especially important to enhance the physical quality of senior citizens and promote their health condition.

\section{Survey on the status quo of physical health condition of senior citizens in Qingdao}

\subsection{Survey respondents and method}

We made a survey on senior citizens with the age of 60 to 69 in Qingdao. The survey adopted the method of combination of testing at fixed time, voluntary participation and random sampling. The number of respondents sampled is based on satisfying the lowest survey sample number, namely, one group with an age group of five years old.

\subsection{Survey sample and data source}

Survey sample included physical examination sample and physical test sample, while physical examination sample contained random sampling and voluntary participation in physical test and physical test sample contained the normal group of people selected in physical test sample (here normal group means those patients who are able to take part in all sports exercise and have the capacity of activities, without any acute disease). The fixed-time testing station and the subject group cooperated to make a sampling test. This survey had great difficulty, and the number of actual respondents was 372, and the effective sample was 270 (including 134 male and 136 female).

\subsection{Major survey content}

Body pattern indexes include height, weight, waistline, chest circumference and hip circumference. 
Body function indexes include vital capacity; physical quality indexes include grip strength, sit-and-reach, choice reaction time and stand on one leg.

\subsection{Evaluation method and criterion}

Evaluation of a single index adopted the evaluation method of 5 -grade marking system. The evaluation criterion for the same age group was similar and the evaluation criterion was also the evaluation criterion of a single index. That is, five scores was excellent, four scores was good, 3 scores was medium, 2 scores was medium-low and 1 score was bad. The overall evaluation was based on the total tested items of testees. The evaluation grade was classified into four grades: the first grade (excellent), the second grade (good), the third grade (passing) and the fourth grade (no passing). The overall evaluation criterion was that, below 13 stands for no passing, 14-18 stands for passing, 19-22 stands for good and above 23 stands for excellent.

\section{Result and analysis}

\subsection{Evaluation on physical quality of senior citizens in Qingdao in 2007}

According to requirements of "Citizens' Physical Test Working Project in Qingdao in 2007", the major testing objects are the urban senior citizens with an age of 60-69 in physical test among senior citizens in Qingdao.

\section{Insert Table 1 Here}

4.1.1 Distribution of fatness and thinness of senior citizens

From Table 2, it can be found that, there are appropriately $62.2 \%$ senior citizens in Zhoukou with a normal weight, appropriately $26 \%$ with a slight fat weight and $11.8 \%$ senior citizens with a slight thin weight.

\section{Insert Table 2 Here}

4.1.2 Distribution of overall evaluation based on age group and grouping of gender

From Table 3, it can be found that, there are more than one third of senior citizens with an age of 60-69 who have an abnormal weight, and female are better than male.

\section{Insert Table 3 Here}

\section{Conclusion and suggestions}

\subsection{Conclusion}

Generally speaking, the physical health condition of senior citizens in Qingdao is optimistic, but there also exists certain hidden danger. It is discovered through a test of almost ten indexes in the four aspects of body patterning, physiological function, physical quality and health condition of senior citizens in Qingdao and a comparison between this test and previous survey results, that physical condition of female is superior to that of male. However, with growth of age, physical condition of both female and male declines, and especially overweight and decline of cardio-pulmonary function account for a great proportion, which will necessarily exert influences upon the overall health condition. With regard to the problems existing in physical health condition of senior citizens, we have to take feasible and effective measures to promote physical health of the group of senior citizens towards the direction of healthy development

\subsection{Suggestions}

\subsubsection{Sports exercise to enhance physical health of senior citizens}

Senior citizens should do sports exercise according to exercise prescription. Exercise prescription can enable people to do exercises with a definite purpose and plan and in a scientific way. In the case when the exercise prescription can't be made, physical examination and exercise stress test have to be made prior to sports exercises. At the beginning, the amount of exercise ought to be small and then gradually enlarged, even with effective strength and effective time.

\subsubsection{To select sports activities that are suitable for senior citizens}

It is not appropriate for senior citizens to select sports items with fast speed and great physical strength. Instead, they ought to select a whole-body exercise item that can enhance the cardio-pulmonary function and is centered with aerobic metabolism, such as, taking a walk, jogging, Tai Chi, Qi Gong, setting-up exercises and swimming, etc.

\subsubsection{To strengthen medical supervision in the process of activities}

The purpose of strengthening medical supervision is for consideration of security, avoiding over fatigue or accidental injury. For example, speed should not be fast in jogging, for a fast speed is likely to cause ankle sprain. 
Moreover, those with high blood pressure are likely to meet with a mishap, or may have an angina as a result of oxygen deficit. In the process of jogging, jogging may be alternated with walk, the breath should be as it is in a normal situation, the action should be slow and with rhythm, and any action of labored breathing or excessive exerting is forbidden. Especially, those arteriosclerotic senior citizens should are more supposed to avoid any action that might give rise to abrupt increasing blood pressure, such as, handstand, abrupt lowering one's head, and stoop, etc. Senior citizens should often control their pulse, blood pressure and physical health condition and conduct self-supervision. If smooth breathing, euphoria, slight fatigue, good appetite and sleeping, stable pulse and normal blood pressure are realized after an exercise, then it proves that the amount of exercise is suitable for the physical condition and one can continue to do this exercise. On the contrary, if headache, chest distress, discomfortable heartbeat, inappetence, bad sleeping, obvious fatigue and disgust of exercise occur, then one should adjust in time or temporarily stop exercise for a period of time. In exercise, senior citizens may use immediate pulse and recovery time after the exercise to control the amount of exercise. Usually, we apply the formula of "deduction of one's age with 170" to obtain the immediate pulse standard after doing an exercise, which generally should not exceed 110 times / minute. And recovery to the pulse level before the exercise within five to ten minutes after the exercise is the best.

5.2.4 Senior citizens should follow normal living standard in the process of sports exercise

Senior citizens should pay attention to rational nutrition and eating more food that is easy to digest, with high protein, high vitamin and low fat. They ought to stop smoking, since smoking is likely to give rise to angina and add to the morbidity of lung cancer. And less drinking or stop of drinking can protect the liver.

\section{References}

General Administration of Sport of China. (2003). National Physical Fitness Evaluation Standard. Beijing: People's Education Press.

$\mathrm{Hu}$, Xiaofei, Lian, Bizhen, Chen, Xin et al. (2005). Survey and Research on Health Condition and Living Mode of Sports Teachers in Five Colleges and Universities in Beijing. Journal of Beijing Sport University, (9):1264-1266.

Lu, Yuzhen, Liu, Heju \& Pan, Lifen. (2007). The elderly health status and health promotion strategy. Chinese Journal of Health Education, (3):29.

Ministry of Education and General Administration of Sport of China. (2002). Reading of "Students Constitutional Health Criterion (on trial)". Beijing: People's Education Press.

Research Group for Chinese Students' Physical Quality and Health. (2002). Survey Report on Chinese Students' Physical Quality and Health in 2000. Beijing: Higher Education Pres.

Xie, Yanlong. (1997). Sport Hygiene. Beijing: People's Sports Publishing House.

Table 1. Average value

\begin{tabular}{|l|l|l|l|l|l|l|l|}
\hline Gender & Height/cm & Weight/kg & Sit-and-reach/cm & $\begin{array}{l}\text { Vital } \\
\text { capacity/mL }\end{array}$ & $\begin{array}{l}\text { Grip } \\
\text { strength/kg }\end{array}$ & $\begin{array}{l}\text { Stand on } \\
\text { one } \\
\text { leg/s }\end{array}$ & $\begin{array}{l}\text { Choice } \\
\text { reaction } \\
\text { time/s }\end{array}$ \\
\hline Male & $165 \cdot 74$ & $67 \cdot 33$ & $2 \cdot 74$ & $2291 \cdot 93$ & $36 \cdot 13$ & $7 \cdot 51$ & $0 \cdot 79$ \\
\hline Female & $153 \cdot 14$ & $57 \cdot 49$ & $8 \cdot 91$ & $1617 \cdot 72$ & $24 \cdot 02$ & $9 \cdot 09$ & $0 \cdot 81$ \\
\hline
\end{tabular}


Table 2. Distribution of fatness and thinness of senior citizens

\begin{tabular}{|l|l|l|l|l|l|l|l|l|l|l|}
\hline Gender & Number & $\begin{array}{l}\text { Fat/ } \\
\text { person }\end{array}$ & $\begin{array}{l}\text { Fat } \\
/ \%\end{array}$ & $\begin{array}{l}\text { Slightly } \\
\text { fat / } \\
\text { person }\end{array}$ & $\begin{array}{l}\text { Slightly } \\
\text { fat } / \%\end{array}$ & $\begin{array}{l}\text { Slightly } \\
\text { thin/ } \\
\text { person }\end{array}$ & $\begin{array}{l}\text { Slightly } \\
\text { thin } / \%\end{array}$ & $\begin{array}{l}\text { Thin } \\
\text { and } \\
\text { weak/ } / \\
\text { person }\end{array}$ & $\begin{array}{l}\text { Thin } \\
\text { and } \\
\text { weak } \\
/ \%\end{array}$ & $\begin{array}{l}\text { Normal } \\
/ \text { person }\end{array}$ \\
\hline Male & 134 & 22 & $16 \cdot 4$ & 22 & $16 \cdot 4$ & 10 & $7 \cdot 5$ & 4 & 3 & $56 \cdot 7$ \\
\hline Female & 136 & 16 & $11 \cdot 8$ & 10 & $7 \cdot 4$ & 12 & $8 \cdot 8$ & 6 & $4 \cdot 4$ & $67 \cdot 6$ \\
\hline Total & 270 & 38 & $14 \cdot 1$ & 32 & $11 \cdot 9$ & 22 & $8 \cdot 1$ & 10 & $3 \cdot 7$ & $62 \cdot 2$ \\
\hline
\end{tabular}

Table 3. Distribution of fatness and thinness based on age groups

\begin{tabular}{|l|l|l|l|l|l|l|l|l|l|l|l|}
\hline $\begin{array}{l}\text { Age } \\
\text { group }\end{array}$ & Gender & Number & $\begin{array}{l}\text { Fat/ } \\
\text { person }\end{array}$ & $\begin{array}{l}\text { Fat } \\
\text { \% }\end{array}$ & $\begin{array}{l}\text { Slightly } \\
\text { fat } \\
\text { person }\end{array}$ & $\begin{array}{l}\text { Slightly } \\
\text { fat/\% }\end{array}$ & $\begin{array}{l}\text { Slightly } \\
\text { thin/ } \\
\text { person }\end{array}$ & $\begin{array}{l}\text { Slightly } \\
\text { thin } / \%\end{array}$ & $\begin{array}{l}\text { Thin and } \\
\text { weak/ } \\
\text { person }\end{array}$ & $\begin{array}{l}\text { Thin } \\
\text { and } \\
\text { weak } \\
/ \%\end{array}$ & $\begin{array}{l}\text { Normal } \\
\text { person }\end{array}$ \\
\hline $60-64$ & $\mathrm{M}$ & 52 & 10 & 19.2 & 6 & 11.5 & 4 & 7.7 & 0 & 0 & 61.5 \\
& $\mathrm{~F}$ & 80 & 6 & 7.5 & 8 & 10 & 6 & 7.5 & 4 & 5 & 70 \\
\hline $65-69$ & $\mathrm{M}$ & 82 & 12 & 14.6 & 16 & 19.5 & 6 & 7.3 & 4 & 4.9 & 53.4 \\
& $\mathrm{~F}$ & 56 & 10 & 17.9 & 2 & 3.6 & 6 & 10.7 & 2 & 3.6 & 64.5 \\
\hline Total & & 270 & 38 & $14 \cdot 1$ & 32 & $11 \cdot 9$ & 22 & $8 \cdot 1$ & 10 & $3 \cdot 7$ & 249 \\
\hline
\end{tabular}

